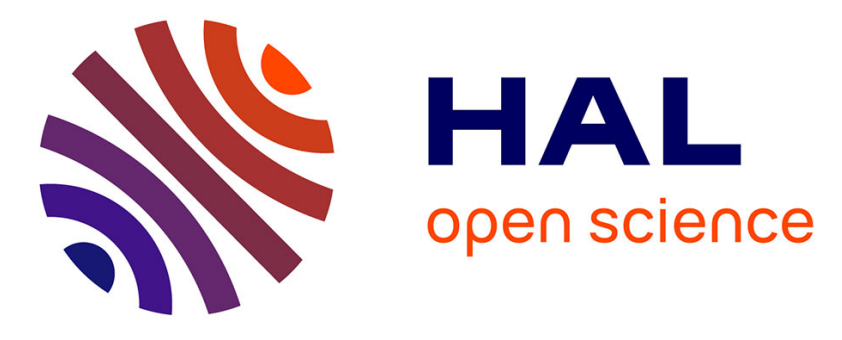

\title{
Decision-Making in a Changing World: A Study in Autism Spectrum Disorders
}

Suzane Robic, Sandrine Sonié, Pierre Fonlupt, Marie-Anne Henaff, Nathalie Touil, Giorgio Coricelli, Jérémie Mattout, Christina Schmitz

\section{To cite this version:}

Suzane Robic, Sandrine Sonié, Pierre Fonlupt, Marie-Anne Henaff, Nathalie Touil, et al.. DecisionMaking in a Changing World: A Study in Autism Spectrum Disorders. Journal of Autism and Developmental Disorders, 2015, 45 (6), pp.1603-1613. 10.1007/s10803-014-2311-7 . hal-02379284

\section{HAL Id: hal-02379284 \\ https://hal.science/hal-02379284}

Submitted on 12 Dec 2019

HAL is a multi-disciplinary open access archive for the deposit and dissemination of scientific research documents, whether they are published or not. The documents may come from teaching and research institutions in France or abroad, or from public or private research centers.
L'archive ouverte pluridisciplinaire HAL, est destinée au dépôt et à la diffusion de documents scientifiques de niveau recherche, publiés ou non, émanant des établissements d'enseignement et de recherche français ou étrangers, des laboratoires publics ou privés. 
Decision-making in a changing world: a study in Autism Spectrum Disorders

Robic $\mathrm{S}^{1,2}$, Sonié $\mathrm{S}^{1,2,3}$, Fonlupt $\mathrm{P}^{1,2}$, Henaff $\mathrm{M}-\mathrm{A}^{1,2}$, Touil $\mathrm{N}^{4}$, Coricelli $\mathrm{G}^{5}$, Mattout $\mathrm{J}^{1,2}$, Schmitz $\mathrm{C}^{1,2}$

${ }^{1}$ Lyon Neuroscience Research Center, Brain Dynamics and Cognition Team; INSERM, U1028; CNRS,

UMR 5292, Lyon, France

${ }^{2}$ University Lyon, France

${ }^{3}$ CEDA, Le Vinatier Hospital, Bron, France

${ }^{4}$ EPICIME-CIC, CHU-Lyon, Bron, France

${ }^{5}$ Laboratoire de Neurosciences Cognitives, INSERM U960, Ecole Normale Supérieure, Paris, France

Corresponding author:

Christina Schmitz: christina.schmitz@inserm.fr

Telephone: +33472138906

Fax: +33472138901 


\begin{abstract}
To learn to deal with the unexpected is essential to adaptation to a social, therefore often unpredictable environment. Fourteen adults with Autism Spectrum Disorders (ASD) and 15 controls underwent a decision-making task aimed at investigating the influence of either a social or a non-social environment, and its interaction with either a stable (with constant probabilities) or an unstable (with changing probabilities) context on their performance. Participants with ASD presented with difficulties in accessing underlying statistical rules in an unstable context, a deficit especially enhanced in the social environment. These results point out that the difficulties people with ASD encounter in their social life might be caused by impaired social cues processing and by the unpredictability associated with the social world.
\end{abstract}

Key words: Autism Spectrum Disorders, Social, Instability, Decision-making 
Autism Spectrum Disorders (ASD) are pervasive developmental disorders characterized by social communication problems, difficulties with reciprocal social interactions, and unusual patterns of repetitive behavior (American Psychiatric Association 2000). Clinical reports show that when left to their own devices, children with ASD tend to compulsively create patterns, which may reflect a strong desire to impose control over changing events (Frith 1970). Kanner observed in children with ASD: "The child's behavior is governed by an anxiously obsessive desire for the maintenance of sameness. Changes in routine can drive him to despair" (Kanner 1968). Individuals with ASD may feel stressed, anxious or confused if unpredictable changes occur in their environment. This greater need for predictability might arise from systemizing mechanism being set too high in ASD (Baron-Cohen 2006). Indeed, according to the hyper-systemizing theory individuals with ASD preferentially develop a systemizing style that makes them good at understanding systems that are highly predictable, with low variance (Baron-Cohen 2002). This theory would explain why people with autism prefer either no change, or systems which change in highly lawful or predictable ways. On the contrary, they might become disabled when faced with systems characterized by complex change (such as social behavior) (Baron-Cohen 2006).

Describing subjects with Asperger syndrome, Volkmar et al. observed that: "their lack of spontaneous adaptation is accompanied by marked reliance on formalistic rules of behavior and rigid social conventions" (Volkmar et al. 2005). Individuals with ASD display difficulties in using their formal social knowledge in quick-paced, rapidly shifting, social situations (Allman et al. 2005). This is illustrated by the compensatory strategy expressed by person with ASD who reported: "When I encounter a new social situation, I have to search my memory for a similar experience that I can use as a model for my next action. I have a very difficult time when I am confronted with unexpected social surprises" (Volkmar et al. 2005). This might partially explain the difficulties they encounter in making "on the spot" decisions: autobiographical accounts describe how decision-making processes can become "locked-up" for people with ASD (Luke et al. 2012).

To learn to deal with the unexpected is essential to adaptation to a social, therefore often unpredictable and fluctuating, environment. The information received in daily social life is inherently probabilistic. Human behavior has been described as a complex, highly unpredictable system (Blackerby 1993). Finding underlying statistical rules (i.e. regularities) and constructing an accurate representation of the world, despite its uncertainty, might be significant challenges for people with ASD (Gomot and Wicker 2012). A recent psychophysical experiment (Ma et al. 2006) indicates that neurotypical people perform near-optimal Bayesian inference (a rational way of updating knowledge with information from the environment) in a wide variety of tasks, ranging from cue integration to decision making. Therefore, social interaction deficits may be linked (among other things) to an inability to extract regularities from the environment. Although social deficits in ASD have often been studied in relation to theory of mind 
(Baron-Cohen et al. 1994; Rutherford et al. 2002; Lombardoet al. 2007), face processing (Ewing et al. 2013; Nagai et al. 2013) and emotion recognition (for a review, see Uljarevic and Hamilton 2012), the processing of the unpredictable aspect of the social world per se has not yet been investigated.

According to Allman et al. (2005), the social disabilities observed in ASD may be partially due to the abnormal development of a specific class of neurons, the Von Economo neurons, which may be involved in the fast intuitive assessment of complex situations. These neurons are located in the anterior cingulate (ACC) and fronto-insular cortex. The authors hypothesized that these neurons enable individuals to make quick, intuitive decisions that enable them to adapt to rapidly changing conditions. Allman et al. further predicted that these deficiencies would be observable in non-social tasks, as well as in social situations (because social emotions, by their very nature, involve considerable uncertainty). There is no clear evidence whether people with ASD have a primary difficulty extracting regularities from any kind of information, or if these difficulties are particularly enhanced in a social environment. Indeed, in individuals with ASD, the difficulties created by the social nature of the environment could interact with a global deficit they have in adapting their behavior to an unstable context.

Our aim was to study the ability of people with ASD to extract regularities from the environment, and to investigate the potential influence of the social nature of the environment on this ability. This behavioral study aimed at investigating the influence of an either social or non-social and stable (associated with constant probabilities) or unstable (associated with changing probabilities) environment on the behavior of ASD participants in a decision-making task.

\section{Material and methods}

\section{Participants}

Fourteen adult participants with ASD without intellectual deficiency (mean age: $28.4 \pm 6.9$ ) took part in this study. Eleven of them did not present with delay in language onset. Fifteen adult control participants with typical development (mean age: $29.4 \pm 8.2$ ) constituted the control group. The volunteers fully consented to the study, which was approved by the French National Ethics Committee. The two groups were matched with respect to age, gender and verbal IQ (see Table 1). ASD subjects were recruited through the Resources Center for Autism in the Vinatier Hospital (Lyon, France). Control subjects were recruited either using a student mailing list, or among friends of researcher colleagues for the older participants.

All participants in the clinical group had been diagnosed before the study. Individuals with a clinical diagnosis of Asperger Syndrom or High-Functioning Autism according to the DSM-IV-TR (American Psychiatric Association 2000) were included in the study. All diagnoses were made by experienced 
clinicians and based on clinical observations of the participants, using the Autism Diagnostic Interview (Couteur et al. 1989) or the Autism Diagnostic Observation Schedule (Lord et al. 1989). Only one of the 14 ASD subjects presented with a comorbidity. This subject also suffered from a bipolar disorder and was taking a treatment at the time of the study, consisting in a serotoninergic antidepressant and an atypical neuroleptic. The reaction times of this subject were not significantly different from the reaction times of the ASD group (t-test, $\mathrm{p}=0.44$ ). Apart from this subject, ASD participants did not take any medication and did not present any comorbidity at the time of the study.

All participants (both control and ASD subjects) also performed the Autism Quotient (AQ) test (BaronCohen et al. 2001), a measure of the extent of autistic traits in adults. Prior to the experiment, the control participants' AQ was calculated in order to verify that their score did not extent the limit of 31 , since Baron-Cohen et al. (2001) cited a score of 32 or more as indicating clinically significant levels of autistic traits. All control subjects met this criterion. $\mathrm{T}$ tests were run to test for statistically significant differences concerning age, gender, verbal IQ, performance IQ and AQ (see Table 1). The performance IQ, but not the verbal one, differed between the two groups. A difference between the verbal and performance IQ is a common finding in persons with ASD without delay in language onset (Chiang et al. 2014; Wilson et al. 2014).

[insert table 1 about here]

Participants received 20 Euros at the end of the experiment.

\section{Design and procedure}

We compared the behavior of ASD patients and matched controls in a decision task. The task was adapted from Behrens and collaborators (Behrens et al. 2007; 2008). Participants were presented with two boxes with hidden reward probabilities, and were asked to choose between them by pressing one of the two available buttons on a regular keyboard. The goal was to score as many points as possible. In each trial, if one box was rewarding, the other was not. Participants received feedback about their choice at the end of the trial and their score was updated accordingly. To avoid stress in participants, especially in those with ASD, subjects had no time limitation to choose one of the two boxes, but they were asked to answer as soon as their choice was made. 
All participants carried out a familiarization task first. In this familiarization task, participants did not receive a cue before making their choice. The boxes had hidden probabilities that varied during the session (120 trials): during the first 60 trials, the probability of winning was $75 \%$ for one box, and $25 \%$ for the other box (stable context). During the last 60 trials, the probabilities associated with the boxes were unstable, switching from $20 \%$ to $80 \%$ twice over the 60 trials (unstable context). Participants needed to have experienced a "stable" context in order to induce an "unstable" context. Therefore, in this familiarization task, the stable condition was always performed before the unstable condition.

Participants then performed the cue-guided task: a cue (either non-social or social) was presented to subjects at the beginning of each trial, before they made their choice. In the non-social environment, the cue was an arrow (indicating a computer's choice) and was presented to subjects for $800 \mathrm{~ms}$. In the social environment, a short movie depicting the choice of an actor was presented to subjects for $1500 \mathrm{~ms}$ before each trial. In this movie, the actor dynamically indicated his choice by looking at the chosen box, and the chosen box then lit up (see Fig. 1). Stimuli presentation was mediated by the Presentation software (Neurobehavioral Systems, EU).

[insert Fig. 1 about here]

Participants underwent three distinct conditions (60 trials each, see Table 2) in both non-social and social environments. Different hidden probabilities of indicating the correct answer were associated with the cue and different hidden probabilities of winning were attributed to the boxes.

[insert table 2 about here]

(1) " $80 \%$ reliable cue": the probabilities of winning were greater when following the cue (reliable in $80 \%$ of trials) than when following the box probabilities ( $60 \%$ for one of the boxes). Cue reliability was stable.

(2) " $60 \%$ reliable cue": the probabilities of winning were greater when relying on the box probabilities ( $80 \%$ for one of the boxes) than when following the cue (reliable in $60 \%$ of trials). Cue reliability was stable. 
(3) "Unstable cue reliability": cue reliability was unstable, switching from $80 \%$ reliable to $80 \%$ unreliable twice over the 60 trials. The probabilities of winning were greater when following the cue (choosing the opposite of the cue indication when the cue was $80 \%$ unreliable, or following its indication when it was $80 \%$ reliable) than when following the box probabilities ( $60 \%$ for one of the boxes).

Inside each group (ASD and control subjects), half of the participants performed the experiment with order 1: \{Familiarization task; "Non-social 80\% reliable cue"; "Non-social 60\% reliable cue"; "Non-social unstable cue reliability"; "Social $80 \%$ reliable cue"; "Social $60 \%$ reliable cue"; "Social unstable cue reliability"\}; and half of the participants performed the experiment with order 2: \{Familiarization task; "Social 80\% reliable cue"; "Social 60\% reliable cue"; "Social unstable cue reliability"; "Non-social 80\% reliable cue"; "Non-social $60 \%$ reliable cue"; "Non-social unstable cue reliability" $\}$. The color of the boxes was also counterbalanced between subjects to avoid an effect of color preference.

Variables of interest defined for the behavioral analysis

We used different variables to quantify the subjects' behavior.

- the subjects' reaction time and performance (calculated as the proportion of trials won in each condition).

- success criterion: defined as winning $60 \%$ of trials relative to the total number of trials. Reaching the success criterion was a Boolean equal to 1 if the subject's performance was higher than $60 \%$, and equal to 0 if it was lower. This enabled to extract for each group the percentage of subjects achieving the success criterion in the different conditions.

- index of perseveration after a failure: number of trials between a failure and a change of choice.

- proportion of trials in which the subject followed the cue: calculated in each condition relative to the total number of trials.

\section{Statistical analysis}

The subjects' reaction time, the performance, the index of perseveration after a failure and the proportion of trials in which the subject followed the cue were analysed with multifactorial ANOVAs. Multifactorial ANOVAs aimed at understanding which factor better explains each variable of interest.

In the familiarization task we were interested in the influence of three factors :

(1) the "subject" factor enabled to study how each variable was explained by the fact that each subject is different from the other. This factor was not linked to our protocol : it was a random factor. The "subject" factor had 29 levels, corresponding to the number of subjects. 
(2) the "group" factor enabled to study the effect of being part of the ASD group compared to being part of the control group on the variable of interest. This factor was defined in our protocol, it was a fixed factor. This "group" factor had two levels, corresponding to the "ASD group" and the "control group"

(3) the "stability" factor enabled to study the effect of being in an unstable context compared to being in a stable one on the variable of interest. This factor was also defined in our protocol, it was a fixed factor and it held two levels: "stable" and "unstable", corresponding to the two kinds of context.

The "subject" factor was random, the other ones were fixed. We therefore used a mixed-effect model to analyse the data.

In the cue-guided task we were interested in the influence of the same three factors as those from the familiarization task model : "subject", "group" and "stability", and two supplementary factors linked to the supplementary conditions of this task :

(4) the "social nature" factor enabled to study the effect of being in a social environment compared to be in a non-social one on the variable of interest. This factor was defined in our protocol, it was a fixed factor and it held two levels: "non-social" and "social", corresponding to the two kinds of environment.

(5) the "reliability" factor enabled to study the effect of receiving an information more or less reliable on the variable of interest. This factor was also defined in our protocol, it was a fixed factor and it held three levels: " $20 \%$ reliable", " $60 \%$ reliable", and " $80 \%$ reliable".

The "subject" factor was random, the other ones were fixed. We therefore also used a mixed-effect model. As a non parametric equivalent for 3 ways ANOVA test does not exist, it is generally admitted to use the parametric approach to analyze a multifactorial (more than 2 factors) design even if the distribution of the studied variable deviate from the normal distribution. Moreover, parametric statistical analyses are widely used even with small sample sizes as the ANOVA is very robust (i.e., not creating effects in case of assumption violation, Schmider et al. 2010).

Post-hoc tests were applied to compare groups (Bonferroni multiple comparison test). Before each Bonferroni multiple comparison test, the equality of variances was checked. If the variables in the two groups had equal variances, the degrees of freedom had a value of 27 (= number of subjects -2 ). In this case the value of the degrees of freedom was reported in the result section. If the variables in the two groups had unequal variances, the degrees of freedom were calculated with the Welch Correction. In this case the corrected value of the degrees of freedom was reported in the result section.

To compare the success criterion between the 2 groups, we used a "proportion comparison test" (Schwartz 1963). 


\section{Results}

\section{Reaction times}

We were first interested in whether the ASD and control groups differed in terms of their reaction time. Regardless of the condition, ANOVA showed slower reaction times in ASD subjects compared to controls in both the familiarization task and the cue-guided task $(\mathrm{P}<0.001, \mathrm{~T}=15.96$, corrected degrees of freedom $=23$ ).

\section{Performances}

We were then interested in whether the ASD and control groups differed in terms of their performances (percentage of trials won). ANOVA showed an effect of the "group" factor in the familiarization task and in the cue-guided task. In the familiarization task, ASD subjects' performances were significantly lower than controls' $(\mathrm{P}<0.01, \mathrm{~T}=3.03$, corrected degrees of freedom $=27)$, successful trial percentage was $55 \%( \pm 7.2)$ for ASD and $60 \%( \pm 7.1)$ for controls. A difference between the two groups' performances was also found in the cue-guided task $(\mathrm{P}<0.001, \mathrm{~T}=6.39$, corrected degrees of freedom $=25)$ : the percentage of successful trials was $58.2 \%( \pm 16.1)$ for ASD subjects and $66.6 \%( \pm 11.8)$ for controls. ANOVA also showed an effect of stability on the subjects' performances: regardless of the group, subjects showed lower performance $(\mathrm{P}<0.001, \mathrm{~T}=9.18$, degrees of freedom $=27)$ in the unstable context $(58.7 \% \pm 15.9$ of successful trials) compared to the stable one $(68.2 \% \pm 10.1$ of successful trials). No interaction between the factors "stability" and "group" was found.

We also tested whether the AQ could be negatively correlated with performances in the unstable conditions and in the social ones. In the familiarization task and the cue-guided task, a significant negative correlation between $\mathrm{AQ}$ and performances was found (in the familiarization task: $\mathrm{R}=-0.41$ and $\mathrm{P}<0.05$; in the cue-guided task: $\mathrm{R}=-0.5$ and $\mathrm{P}<0.01)$. Considering the different sessions separately, a significant negative correlation between $\mathrm{AQ}$ and performances was found in all unstable conditions (in the familiarization task: $\mathrm{R}=-0.42, \mathrm{P}<0.05$, in the non-social environment: $\mathrm{R}=-0.53, \mathrm{P}<0.01$, in the social environment: $\mathrm{R}=-0.53, \mathrm{P}<0.01)$. This correlation was also found in the " $80 \%$ reliable cue" social condition $(\mathrm{R}=-0.41, \mathrm{P}<0.05)($ Fig. 2$)$.

[insert Fig.2 about here] 


\section{Success criterion}

We compared the success criteria to test whether the ASD and control groups differed in terms of the number of subjects succeeding in the task. In each condition, the success criterion was defined as winning $60 \%$ of trials relative to the total number of trials (see methods). The percentage of subjects achieving the success criterion was significantly lower in the ASD group compared to the control group in the unstable context $(\mathrm{P}<0.001, \mathrm{Z}=3.30)$, but not in the stable one, and in the social environment but not in the nonsocial one $(\mathrm{P}<0.05, \mathrm{Z}=1.93$, Fig. 3$)$. Both a social environment and an unstable context were associated with a lower number of ASD subjects reaching the success criterion, but the unstable context affected this number more than the social environment $(\mathrm{P}<0.01, \mathrm{Z}=2.65)$.

[insert Fig. 3 about here]

\section{Perseveration after a failure}

We were also interested in whether the ASD and control groups differed in terms of perseveration. The number of trials between a failure and a change of choice was calculated. ANOVA applied to this parameter showed that regardless of the condition, ASD subjects perseverated significantly longer than controls after a failed trial $(\mathrm{P}<0.001, \mathrm{~T}=5.45$, corrected degrees of freedom $=27)$ : the number of trials between a failure and a change of choice was on average $3.2( \pm 1.8)$ trials for ASD subjects compared to $2.3( \pm 1.7)$ trials for controls. Moreover, a significant positive correlation between AQ and the number of trials between a failure and a change of choice was found in the unstable conditions $(\mathrm{R}=0.47 ; \mathrm{P}<0.01)$ but not in the stable ones.

\section{Proportion of trials in which the subject followed the cue}

In the cue-guided task, we tested whether the ASD subjects differed from controls concerning their tendency to follow the cue in the different conditions. The proportion of trials in which the subject followed the cue indication was calculated in each condition. Interactions were found between "group" and "social" factors, and between "group" and "reliability" factors. Post-hoc tests revealed a difference between the extent to which ASD participants and controls followed the cue when the cue was $20 \%$ reliable $(\mathrm{P}<0.01, \mathrm{~T}=3.11$, corrected degrees of freedom $=25)$, and when it was $80 \%$ reliable $(\mathrm{P}<0.001$, $\mathrm{T}=8.79$, degrees of freedom $=27$ ), regardless of the condition (social and non-social conditions pooled together) (Fig. 4).

[insert Fig.4 about here] 
With regard to the extent to which subjects followed the cue, a significant difference was found in the controls when comparing the " $20 \%$ reliable cue" and the " $60 \%$ reliable cue" conditions $(\mathrm{P}<0.001, \mathrm{~T}=$ 6.63 , degrees of freedom $=27$ ), and when comparing the " $60 \%$ reliable cue" and the " $80 \%$ reliable cue" $(\mathrm{P}<0.001, \mathrm{~T}=12.74$, degrees of freedom $=27)$. In ASD subjects, a significant difference was only found between the " $20 \%$ reliable cue" and the " $80 \%$ reliable cue" conditions $(\mathrm{P}<0.001, \mathrm{~T}=4.87$, degrees of freedom $=27)$.

The correlation between the extent to which controls followed the cue and cue reliability was very strong: $\mathrm{R}=0.8410(\mathrm{P}<0.001)$. In ASD subjects the correlation between these two values was also significant but lower: $\mathrm{R}=0.423(\mathrm{P}<0.01)$. More precisely, only one subject out of the 15 controls showed a correlation coefficient between the extent to which he followed the cue and cue reliability lower than 0.8 , whereas 7 subjects out of the 14 ASD subjects showed a correlation coefficient below 0.8 (Fig. 5).

[insert Fig.5 about here]

We also hypothesized that the AQ could be negatively correlated with the extent to which subjects followed a cue mostly reliable, and that it could be positively correlated with the extent to which subjects followed a cue mostly non-reliable. When cue reliability was unstable, the cue could be either $80 \%$ or $20 \%$ reliable. In the unstable condition (cue reliability shifting from $80 \%$ to $20 \%$ ), we found a negative significant correlation between AQ and the extent to which subjects followed the cue when cue reliability was $80 \%$ (regardless of the social nature of the environment) (with a non-social cue : $\mathrm{R}=-0.42, \mathrm{P}<0.05$; with a social cue: $\mathrm{R}=-0.44, \mathrm{P}<0.05)$. Conversely, a positive correlation between $\mathrm{AQ}$ and the extent to which subjects followed the cue indication was found in the unstable social environment, when the cue was only $20 \%$ reliable $(\mathrm{R}=0.39, \mathrm{P}<0.05)$ (Table 3$)$.

[insert Table 3 about here]

\section{Discussion}

This study aimed at investigating the influence of an either social or non-social environment on the behavior of people with ASD, and its interaction with an either stable or unstable context. Our aim was to study their ability to extract regularities from the environment, and to investigate the potential influence of 
the social nature of the environment on it. We found that both social environment and unstable context made it difficult to integrate cues in decision making, and that the negative impact of an unstable context on ASD subjects' performances was dramatically higher than that of the social environment. Based on the fact that the success criterion of the two groups did not differ in the non-social environment and in the stable context, it is unlikely that a difference between the two groups in the performance IQ could explain the lower performance of the ASD group in the social and in the unstable context. Cue processing and the ability to use it as a function of its reliability were especially impaired in an environment presenting both social and unstable components. We also found that ASD subjects had difficulty taking cue reliability into account in their decision making.

\section{1- Characterization of the difficulties experienced by people with ASD when facing an unstable context}

Although both ASD and control groups showed lower performances in the unstable context, the percentage of subjects succeeding in the task (i.e. achieving the success criterion, defined as winning $60 \%$ of trials) was dramatically lower in the ASD group compared to the control one. Moreover, the performance correlated negatively with AQ in all the unstable conditions. Since AQ scores were significantly different between the two groups, these results suggest that ASD subjects experienced more difficulties in an unstable context than neurotypical subjects. Further, a significant positive correlation between AQ scores and perseveration after a failure was only found in the unstable context, suggesting that the unstable context enhanced perseveration behavior in ASD subjects. Moreover, in the unstable context, when the cue was mostly reliable, the extent to which participants followed it negatively correlated with the AQ, revealing an increased difficulty in ASD subjects to appropriately use the cue in the unstable context.

These results indicate that an unstable context impacts ASD subjects' performances in two ways: it enhances their perseveration after a failure, and it makes it more difficult for them to use the cue in an appropriate way (i.e. according to its reliability). At the sensory level, it has been shown that the processing of irregularities may be aberrant in ASD (Gomot and Wicker 2012), but this is the first time that this result has been shown at a cognitive level, in a task requiring the integration of irregularities from the environment in a decision-making process. This speaks in favor of a core (non-social) deficit and calls for future studies that would combine such clear behavioral effects with neuroimaging and computational approaches to refine our understanding of this underlying mechanisms and its interaction with social contexts. This is in line with very recent attempts to propose or revisit global theories of ASD (Qian and Lipkin 2011; Pellicano and Burr 2012; Friston et al. 2013). 
An impaired ability to track the instability of the context could explain the preserved performances in the stable context and poorer performances in the unstable one. Using a task similar to ours, Behrens and collaborators (Behrens et al. 2007; 2008) showed that neurotypical subjects assess the context instability in an optimal manner and adjust decision-making accordingly. They also disclosed that this optimal estimation of volatility was reflected in the fMRI signal in the anterior cingulate cortex (ACC), a region which has been shown to be dysfunctional in ASD subjects (Chiu et al. 2008; Thakkar et al. 2008; Dichter et al. 2009; Agam et al. 2010). Furthermore, the variations in the ACC signal across the neurotypical population reported in Behrens'studies predicted variations in subject ability to update the information. We propose that the estimation of volatility involving the ACC is impaired in ASD subjects. This could make it difficult to update their previous knowledge in an unstable context, leading to an inadaptive use of the context information and consequently resistance to change.

\section{2- An interaction between the social nature of the environment and its instability}

The percentage of subjects succeeding in the task in a social environment was significantly lower in the ASD group than in the control group. We also found a strong negative correlation between AQ and performance in all social conditions, suggesting that the social nature of the environment adds a supplementary difficulty for people with ASD. Further, in the social environment, when the cue was mostly reliable, the AQ was negatively correlated to the extent to which the subjects followed it. The alteration of the performance in the social environment could not be explained by mere deficits in joint attention, as the actor's choice was expressed both by his gaze turning towards the chosen box and by the lit box. These results indicate that the social environment impacts ASD subjects' performances by making it more difficult for them to use the cue in an appropriate way (i.e. according to its reliability).

Whereas some studies have not shown any behavioral differences between ASD subjects and controls in terms of orienting toward social stimuli (Greene et al. 2011; Pruett et al. 2011), other studies have shown that subjects with ASD fail to orient to social cues (Dawson et al. 1998; Sasson et al. 2007; Klin et al. 2009). In our task, the negative correlation between AQ and performance was only found in the social conditions requiring the use of the cue, whereas it was not found in the social conditions requiring the cue to be ignored. This indicates that despite their difficulty in appropriately using a social cue, ASD subjects were perfectly able to ignore an irrelevant social cue. For ASD subjects, the easiest way of processing a social cue was to ignore it. This argument is in favor of the hypothesis of a global failure to orient to relevant social stimuli.

We found that both social environment and unstable context made it harder to integrate cues in decision making, and that the negative impact of an unstable context on ASD performances was dramatically 
higher than that of the social environment. When the environment was both social and unstable, a correlation was found between the AQ and the tendency to follow the non-reliable cue. This correlation was not found in the non-social unstable condition, suggesting an interaction between the social nature of the environment and its instability: a social unstable environment seems more puzzling than a social stable environment or than a non-social unstable environment. Cue processing and the ability to use it as a function of its reliability seems especially impaired in an environment presenting both social and unstable components.

\section{3- Difficulty using the cue as a function of its reliability}

Independently of the negative impact of both social environment and unstable context on the ASD subjects' performances, we found that ASD subjects also had a global difficulty modulating their decision as a function of the reliability of the cue. This result is in line with the study of Ames and Jarrold (2007), which showed that children with ASD present difficulties in using arbitrary cues, both social and nonsocial, to make inferences, suggesting a cue inference deficit associated with ASD. A similar suggestion was made by Leekam and collatorators (Leekamet al. 2000) in a study investigating attention orienting in children with ASD. Although individuals with ASD had no difficulties in orienting their attention in response to exogenous cueing (an object appears in the periphery), they showed deficient endogenous cueing (a directional cue appears in a central position). Individuals with ASD may be able to orient their attention in response to simple, low-level cues, but they may have difficulty in using high-level cues, regardless of whether such cues are social or not. These arguments have clear parallels with the idea proposed by De Martino and collaborators (De Martino et al. 2008), that is people with ASD present a global insensitivity to contextual frame. In this study, subjects performed a financial task in which the monetary prospects were presented as either loss or gain. Whereas control subjects manifested susceptibility to this framing effect, which was reflected in an increased disposition to gamble in loss compared with gain frames, ASD subjects made more consistent choices and showed no differential skin conductance response to the contextual manipulation, suggesting a reduced behavioral susceptibility to a framing effect in subjects with ASD.

However, we noted in our study that 7 out of the 14 ASD subjects appropriately modulated their decision as a function of the reliability of the cue. This means that the difficulties in processing a cue do not seem to affect all ASD subjects. Nevertheless, this preserved ability did not appear to be linked to the extent of autistic traits, since we did not find any correlation between the extent to which the subjects followed the cue indication and their AQ.

\section{Conclusion}


In conclusion, cue processing, together with the social nature of the environment and its unpredictability, cause difficulties for people with ASD. We showed here that people with ASD present a global difficulty in accessing underlying statistical rules (regularities), and that this deficit is especially enhanced in a social environment. The difficulties encountered by people with ASD in a social environment may be caused by both impaired social processing and by the unpredictability associated with the social world.

Our results support Allman et al. (2005) theory, suggesting that the social disabilities observed in ASD may be linked to a deficit in the fast intuitive assessment of complex situations. This calls for future studies that would combine such clear behavioral effects with functional MRI and computational approaches to investigate the ability of people with ASD to build flexible predictions in a changing context. This is in line with very recent attempts to propose or revisit global theories of ASD (Qian and Lipkin 2011; Pellicano and Burr 2012; Friston et al. 2013). However the relatively small sample size in our study might be seen as a limitation and similar tests on bigger sample size should be made to confirm our results. This view could contribute to building specific clinical and educational intervention programs in order to provide ASD patients with specific cognitive strategies to overcome prediction weaknesses. We propose that therapy should focus on training people with ASD to learn regularities in both social and non-social domains.

\section{Acknowledgments}

We would like to thank all of the participants for making this research possible. This study was supported by a Scientific Research Council grant from the Vinatier Hospital Center; the work was performed within the framework of the LABEX CORTEX (ANR-11-LABX-0042) of Universite de Lyon, within the program "Investissements d'Avenir" (ANR-11-IDEX-0007) operated by the French National Research Agency (ANR).

\section{References}

Agam, Y., Joseph, R. M., Barton, J. J. S., \& Manoach, D. S. (2010). Reduced cognitive control of response inhibition by the anterior cingulate cortex in autism spectrum disorders. NeuroImage, 52(1), 336-347. doi:10.1016/j.neuroimage.2010.04.010

Allman, J. M., Watson, K. K., Tetreault, N. A., \& Hakeem, A. Y. (2005). Intuition and autism: a possible role for Von Economo neurons. Trends in Cognitive Sciences, 9(8), 367-373. doi:10.1016/j.tics.2005.06.008 
Ames, C. S., \& Jarrold, C. (2007). The problem with using eye-gaze to infer desire: a deficit of cue inference in children with autism spectrum disorder? Journal of Autism and Developmental Disorders, 37(9), 1761 - 1775. doi:10.1007/s10803-006-0309-5

American Psychiatric Association. (2000). Diagnostic and Statistical Manual of Mental Disorders, Fourth Edition, Text Revision (DSM-IV-TR). Arlington, VA: American Psychiatric Association.

American Psychiatric Association. (2013). DSM-V Diagnostic and Statistical Manual of Mental Disorders, Fifth Edition, 50-59.

Baron-Cohen, S., Ring, H., Moriarty, J., Schmitz, B., Costa, D., \& Ell, P. (1994). Recognition of mental state terms. Clinical findings in children with autism and a functional neuroimaging study of normal adults. The British Journal of Psychiatry: the Journal of Mental Science, 165(5), 640-649.

Baron-Cohen, S., Wheelwright, S., Skinner, R., Martin, J., \& Clubley, E. (2001). The autism-spectrum quotient (AQ): evidence from Asperger syndrome/high-functioning autism, males and females, scientists and mathematicians. Journal of Autism and Developmental Disorders, 31(1), 5-17.

Baron-Cohen, S. (2002). The extreme male brain theory of autism. Trends in Cognitive Sciences, 6(6), 248 $-254$.

Baron-Cohen, S. (2006). The hyper-systemizing, assortative mating theory of autism. Progress in NeuroPsychopharmacology \& Biological Psychiatry, 30(5), 865-72.

Behrens, T. E. J., Hunt, L. T., Woolrich, M. W., \& Rushworth, M. F. S. (2008). Associative learning of social value. Nature, 456(7219), 245-249. doi: 10.1038/nature07538

Behrens, T. E. J., Woolrich, M. W., Walton, M. E., \& Rushworth, M. F. S. (2007). Learning the value of information in an uncertain world. Nature Neuroscience, 10(9), 1214-1221.

Blackerby, R. F. (1993). Application of Chaos Theory to Psychological Models. Thesis (PH.D.) University of Texas, Austin, 1993, 1285.

Chiang, H. M., Tsai, L. Y., Cheung, Y. K., Brown, A., Li, H. (2014). A meta-analysis of differences in IQ profiles between individuals with Asperger's disorder and high-functioning autism. Journal of

Autism and Developmental Disorders, 44(7), 1577-1596. doi: 10.1007/s10803-013-2025-2

Chiu, P. H., Kayali, M. A., Kishida, K. T., Tomlin, D., Klinger, L. G., Klinger, M. R., \& Montague, P. R. (2008). Self responses along cingulate cortex reveal quantitative neural phenotype for highfunctioning autism. Neuron, 57(3), 463-473. doi:10.1016/j.neuron.2007.12.020

Couteur, A. L., Rutter, M., Lord, C., Rios, P., Robertson, S., Holdgrafer, M., \& McLennan, J. (1989). Autism diagnostic interview: A standardized investigator-based instrument. Journal of Autism and Developmental Disorders, 19(3), 363-387. doi:10.1007/BF02212936

Dawson, G., Meltzoff, A. N., Osterling, J., Rinaldi, J., \& Brown, E. (1998). Children with autism fail to orient to naturally occurring social stimuli. Journal of Autism and Developmental Disorders, 28(6), 479-485.

De Martino, B., Harrison, N. A., Knafo, S., Bird, G., \& Dolan, R. J. (2008). Explaining enhanced logical consistency during decision making in autism. The Journal of Neuroscience, 28(42), 1074610750. doi:10.1523/JNEUROSCI.2895-08.2008

Dichter, G. S., Felder, J. N., \& Bodfish, J. W. (2009). Autism is characterized by dorsal anterior cingulate hyperactivation during social target detection. Social Cognitive and Affective Neuroscience, 4(3), 215-226. doi:10.1093/scan/nsp017

Ewing, L., Pellicano, E., \& Rhodes, G. (2013). Atypical updating of face representations with experience in children with autism. Developmental Science, 16(1), 116-123. doi:10.1111/desc.12007

Friston, K. J., Lawson, R., \& Frith, C. D. (2013). On hyperpriors and hypopriors: comment on Pellicano and Burr. Trends in Cognitive Sciences, 17(1), 1. doi:10.1016/j.tics.2012.11.003

Frith, U. (1970). Studies in pattern detection in normal and autistic children. I. Immediate recall of auditory sequences. Journal of Abnormal Psychology, 76(3), 413-420. 
Gomot, M., \& Wicker, B. (2012). A challenging, unpredictable world for people with Autism Spectrum Disorder. International Journal of Psychophysiology, 83(2), 240-247. doi:10.1016/j.ijpsycho.2011.09.017

Greene, D. J., Colich, N., Iacoboni, M., Zaidel, E., Bookheimer, S. Y., \& Dapretto, M. (2011). Atypical neural networks for social orienting in autism spectrum disorders. NeuroImage, 56(1), 354-362. doi:10.1016/j.neuroimage.2011.02.031

Kanner, L. (1968). Autistic disturbances of affective contact. Acta paedopsychiatrica, 35(4), 100-136.

Klin, A., Lin, D. J., Gorrindo, P., Ramsay, G., \& Jones, W. (2009). Two-year-olds with autism orient to non-social contingencies rather than biological motion. Nature, 459(7244), 257-261. doi:10.1038/nature07868

Leekam, S. R., López, B., \& Moore, C. (2000). Attention and joint attention in preschool children with autism. Developmental Psychology, 36(2), 261-273.

Lombardo, M. V., Barnes, J. L., Wheelwright, S. J., \& Baron-Cohen, S. (2007). Self-Referential Cognition and Empathy in Autism. PLoS ONE, 2(9), e883. doi:10.1371/journal.pone.0000883

Lord, C., Rutter, M., Goode, S., Heemsbergen, J., Jordan, H., Mawhood, L., \& Schopler, E. (1989). Autism diagnostic observation schedule: A standardized observation of communicative and social behavior. Journal of Autism and Developmental Disorders, 19(2), 185-212. doi:10.1007/BF02211841

Luke, L., Clare, I. C. H., Ring, H., Redley, M., \& Watson, P. (2012). Decision-making difficulties experienced by adults with autism spectrum conditions. Autism: the International Journal of Research and Practice, 16(6), 612-621. doi:10.1177/1362361311415876

Ma, W. J., Beck, J. M., Latham, P. E., \& Pouget, A. (2006). Bayesian inference with probabilistic population codes. Nature Neuroscience, 9(11), 1432-1438. doi:10.1038/nn1790

Nagai, M., Bennett, P. J., Rutherford, M. D., Gaspar, C. M., Kumada, T., \& Sekuler, A. B. (2013). Comparing face processing strategies between typically-developed observers and observers with autism using sub-sampled-pixels presentation in response classification technique. Vision Research, 79, 27-35. doi:10.1016/j.visres.2013.01.001

Pellicano, E., \& Burr, D. (2012). When the world becomes « too real »: a Bayesian explanation of autistic perception. Trends in Cognitive Sciences, 16(10), 504-510. doi: 10.1016/j.tics.2012.08.009

Pruett, J. R., Jr, LaMacchia, A., Hoertel, S., Squire, E., McVey, K., Todd, R. D., Constantino, J. N., Petersen, S. E. (2011). Social and non-social cueing of visuospatial attention in autism and typical development. Journal of Autism and Developmental Disorders, 41(6), 715-731. doi: $10.1007 / \mathrm{s} 10803-010-1090-\mathrm{z}$

Qian, N., \& Lipkin, R. M. (2011). A Learning-Style Theory for Understanding Autistic Behaviors. Frontiers in Human Neuroscience, 5(77). doi: 10.3389/fnhum.2011.00077

Rutherford, M. D., Baron-Cohen, S., \& Wheelwright, S. (2002). Reading the mind in the voice: a study with normal adults and adults with Asperger syndrome and high functioning autism. Journal of Autism and Developmental Disorders, 32(3), 189-194.

Sasson, N., Tsuchiya, N., Hurley, R., Couture, S. M., Penn, D. L., Adolphs, R., \& Piven, J. (2007). Orienting to social stimuli differentiates social cognitive impairment in autism and schizophrenia. Neuropsychologia, 45(11), 2580-2588. doi:10.1016/j.neuropsychologia.2007.03.009

Schmider, E., Ziegler, M., Danay, E., Beyer, L., Bühner, M. (2010). Is it really robust? Reinvestigating the robustness of ANOVA against violations of the normal distribution assumption. Methodology: European Journal of Research Methods for the Behavioral and Social Sciences, 6(4), 147-151. doi: 10.1027/1614-2241/a000016

Schwartz, D. (1963). Méthodes statistiques à l'usage des médecins et des biologistes (Flammarion Médecine-Sciences.). 
Thakkar, K. N., Polli, F. E., Joseph, R. M., Tuch, D. S., Hadjikhani, N., Barton, J. J. S., \& Manoach, D. S. (2008). Response monitoring, repetitive behaviour and anterior cingulate abnormalities in autism spectrum disorders (ASD). Brain, 131(9), 2464-2478. doi:10.1093/brain/awn099

Uljarevic, M., \& Hamilton, A. (2012). Recognition of Emotions in Autism: A Formal Meta-Analysis. Journal of Autism and Developmental Disorders, 43(7), 1517-1526. doi:10.1007/s10803-012$1695-5$

Volkmar, F. R., Paul, R., Klin, A., \& Cohen, D. J. (2005). Handbook of Autism and Pervasive Developmental Disorders. In John Wiley \& Sons (Ed.), Vol.1, p. 1283.

Wilson, C. E., Happé, F., Wheelwright, S. J., Ecker, C., Lombardo, M. V., Johnston, P., Daly, C. E., Murphy, C. M., Spain, D., Lai, M-C., Chakrabarti, B., Sauter, D.A., MRC AIMS Consortium, Baron-Cohen, S., Murphy, D. G. M. (2014). The Neuropsychology of Male Adults With HighFunctioning Autism or Asperger Syndrome. Autism Research, 7(5), 1-14. doi: 10.1002/aur.1394 


\section{Figure Captions}

Table 1 Means and standard deviations for age, sex, verbal IQ, performance IQ and AQ of ASD participants and typically developing participants.

Table 2 Summary of the three conditions (60 trials each) in each environment (social and nonsocial).

Table 3 Correlations between AQ and the extent to which all pooled subjects followed the cue.

Fig. 1 Cue-guided task: a cue was presented to subjects at the beginning of each trial, before they made their choice. In the non-social environment (1), the cue was an arrow presented for $800 \mathrm{~ms}$. In the social environment (2), a short movie depicting the choice of an actor was presented for $1500 \mathrm{~ms}$ before each trial. In the movie, the actor dynamically indicated his choice by looking at the chosen box, and the chosen box then lit up. Two boxes with hidden reward probabilities were then presented until the subject chose between them. A yellow frame indicated which box was chosen. Participants then received a feedback about their choice.

Fig. 2 Percentage of successful trials (y-axis) as a function of AQ value (x-axis) in the familiarization task (a), in a non-social environment (b) and in a social one (c). Control subjects are depicted with black circles and ASD subjects with light-grey crosses

Fig. 3 Percentage of ASD and control subjects achieving the success criterion in non-social and social environments (a) and in stable and unstable contexts (b). Asterisks indicate a significant difference between the two groups $(\mathrm{P}<0.001)$.

Fig. 4 Proportion of trials in which controls (black) and ASD subjects (light-grey) followed the cue (y-axis) as a function of cue reliability (x-axis) with standard deviations. Asterisks indicate a significant difference between ASD and control subjects $(\mathrm{P}<0.01)$.

Fig. 5 Representation of the R correlation coefficient (y-axis) between the proportion of trials in which subjects followed the cue and cue reliability, as a function of the AQ (x-axis), in the two pooled populations of control (black circles) and ASD (light-grey crosses) subjects. 


\begin{tabular}{cccc} 
& Controls & ASD & p \\
\hline Age & $28.4 \pm 6.9$ & $29.4 \pm 8.2$ & $\mathrm{~ns}$ \\
F:M & $3: 12$ & $3: 11$ & $\mathrm{~ns}$ \\
Verbal IQ & $126.4 \pm 11.7$ & $118.6 \pm 11.5$ & $\mathrm{~ns}$ \\
Performance IQ & $117.6 \pm 10.2$ & $94.6 \pm 21.5$ & $\mathrm{p}<0.001$ \\
AQ & $13 \pm 7$ & $33 \pm 6$ & $\mathrm{p}<0.001$
\end{tabular}

Table 1: Demographic information (mean $\pm S D$ ): age, gender, verbal IQ, performance IQ and $A Q$ of control and ASD participants.

\begin{tabular}{|c|c|c|c|}
\hline Condition & $\begin{array}{c}\text { (1) } \\
\text { Cue reliability }\end{array}$ & $\begin{array}{c}\text { (2) } \\
\mathbf{6 0 \%} \text { reliable cue }\end{array}$ & $\begin{array}{c}\text { (3) } \\
\text { Unstable cue reliability }\end{array}$ \\
\hline Context & Stable & $60 \%$ & $20 \%-80 \%-20 \%$ \\
\hline Box probabilities & $\begin{array}{c}\text { Box \# 1: } 60 \% \\
\text { Box \# } 2: 40 \%\end{array}$ & $\begin{array}{c}\text { Box \# 1: } 80 \% \\
\text { Box \# 2: } 20 \%\end{array}$ & $\begin{array}{c}\text { Unstable } \\
\text { Box \# 1: } 60 \%\end{array}$ \\
\hline Most efficient strategy & $\begin{array}{c}\text { Follow the cue } \\
\text { indication }\end{array}$ & Ignore the cue & $\begin{array}{c}\text { Do the opposite of the cue indication; } \\
\text { follow it; } \\
\text { do the opposite again }\end{array}$ \\
\hline
\end{tabular}

Table 2: Summary of the three conditions (60 trials each) in each environment (social and non-social)

\section{Conditions}

Non-social environment: $80 \%$ reliable cue

Non-social environment: $60 \%$ reliable cue

Non-social environment: unstable cue reliability: $80 \%$ reliable

Non-social environment: unstable cue reliability: $20 \%$ reliable

Social environment: $80 \%$ reliable cue

Social environment: $60 \%$ reliable cue

Social environment: unstable cue reliability: $80 \%$ reliable

Social environment: unstable cue reliability: $20 \%$ reliable
$\mathbf{R}$

$-\quad 0.09$

$-\quad 0.30$

$-0.42<0.05$

$-\quad 0.13$

$-0.46<0.05$

$-\quad 0.98$

$-0.44<0.05$

$0.39<0.05$

Table 3: Correlations between $A Q$ and the extent to which all pooled subjects followed the cue 


\section{1-Non-social environment}

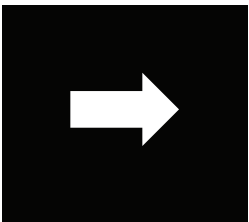

Cue presentation (800 ms)

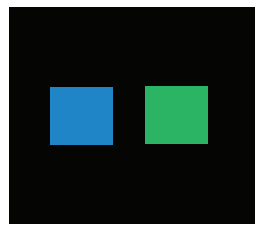

Box presentation

2-Social environment

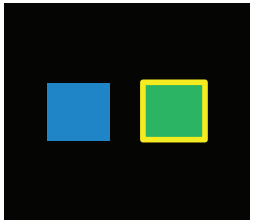

Subject's choice

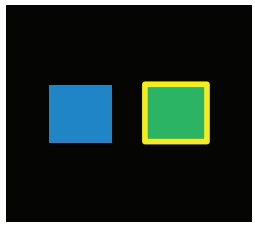

Subject's choice

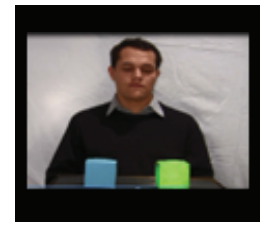

Cue presentation (800 ms)
Box presentation

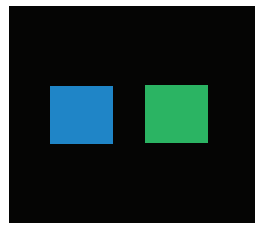

Figure 1

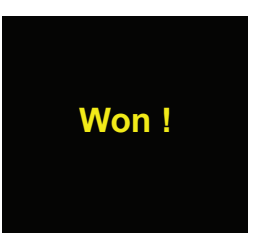

Feedback

(800 ms)

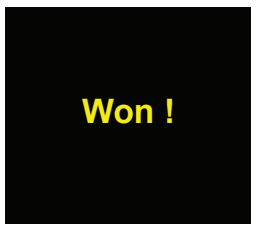

Feedback

(800 ms)

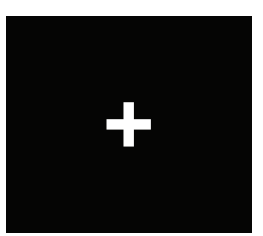

Fixation cross (800 ms)

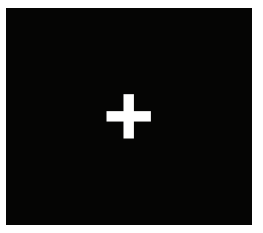

Fixation cross (800 ms) 
a - Familiarization task
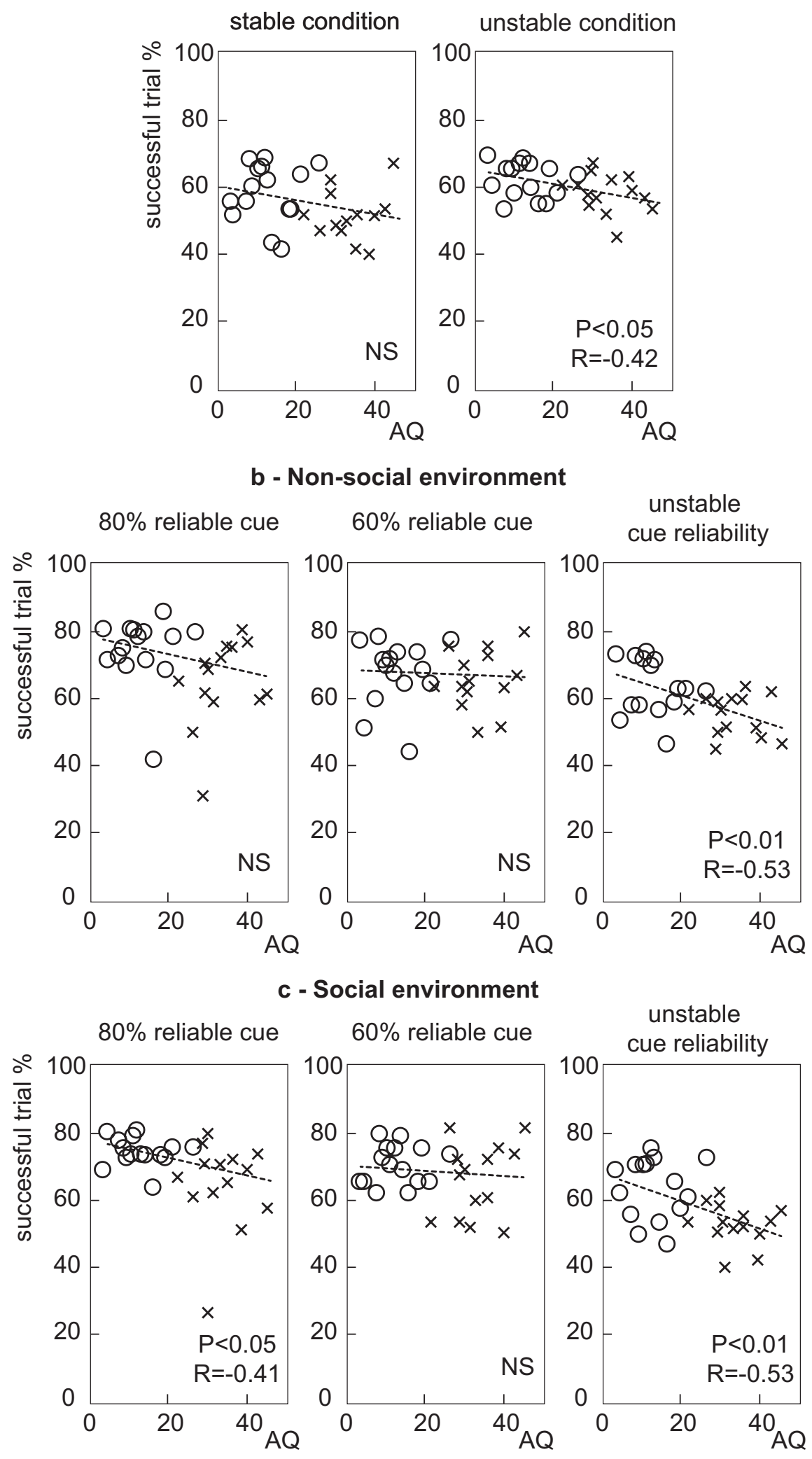

Figure 2 
Percentage of subjects achieving the success criterion
Controls

ASD

b

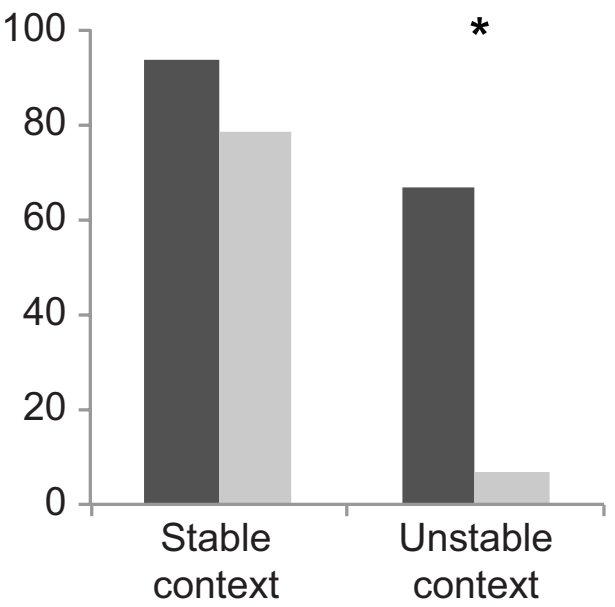

Figure 3

Effect of cue reliability on subject's choice

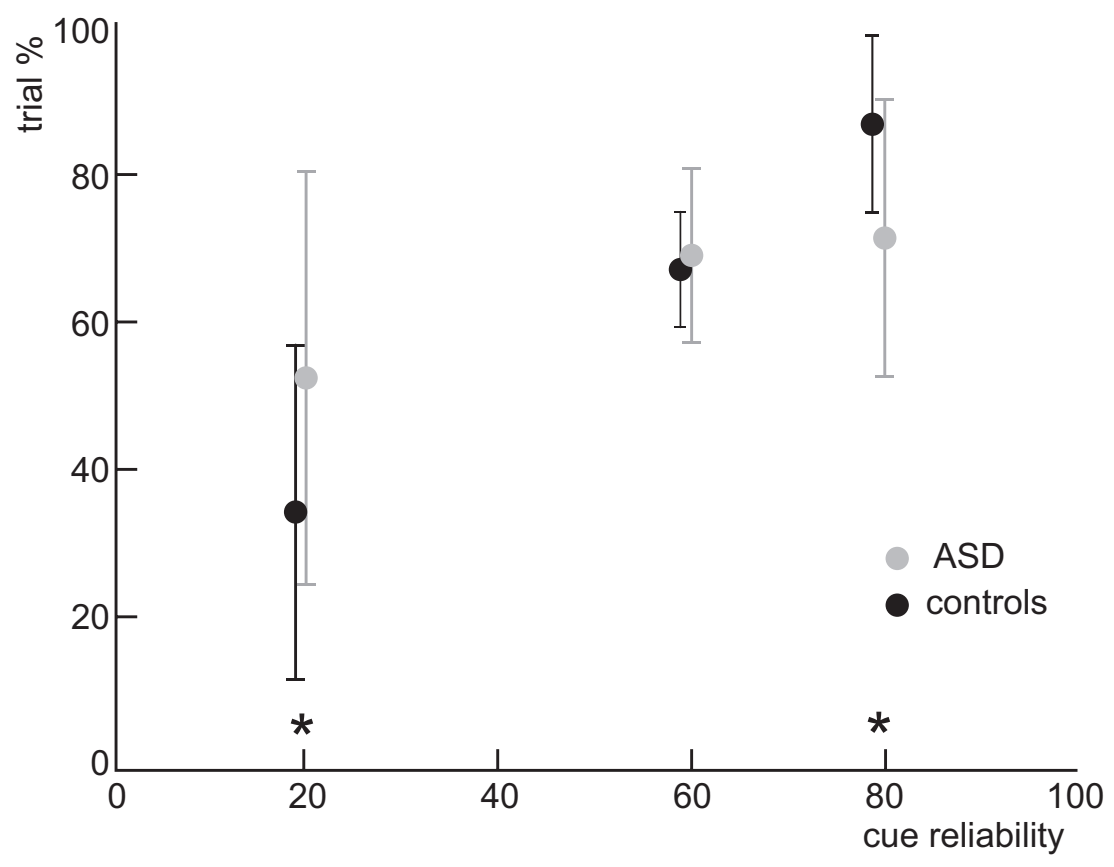

Figure 4 
Correlation between cue reliability and subject's choice, as a function of $A Q$

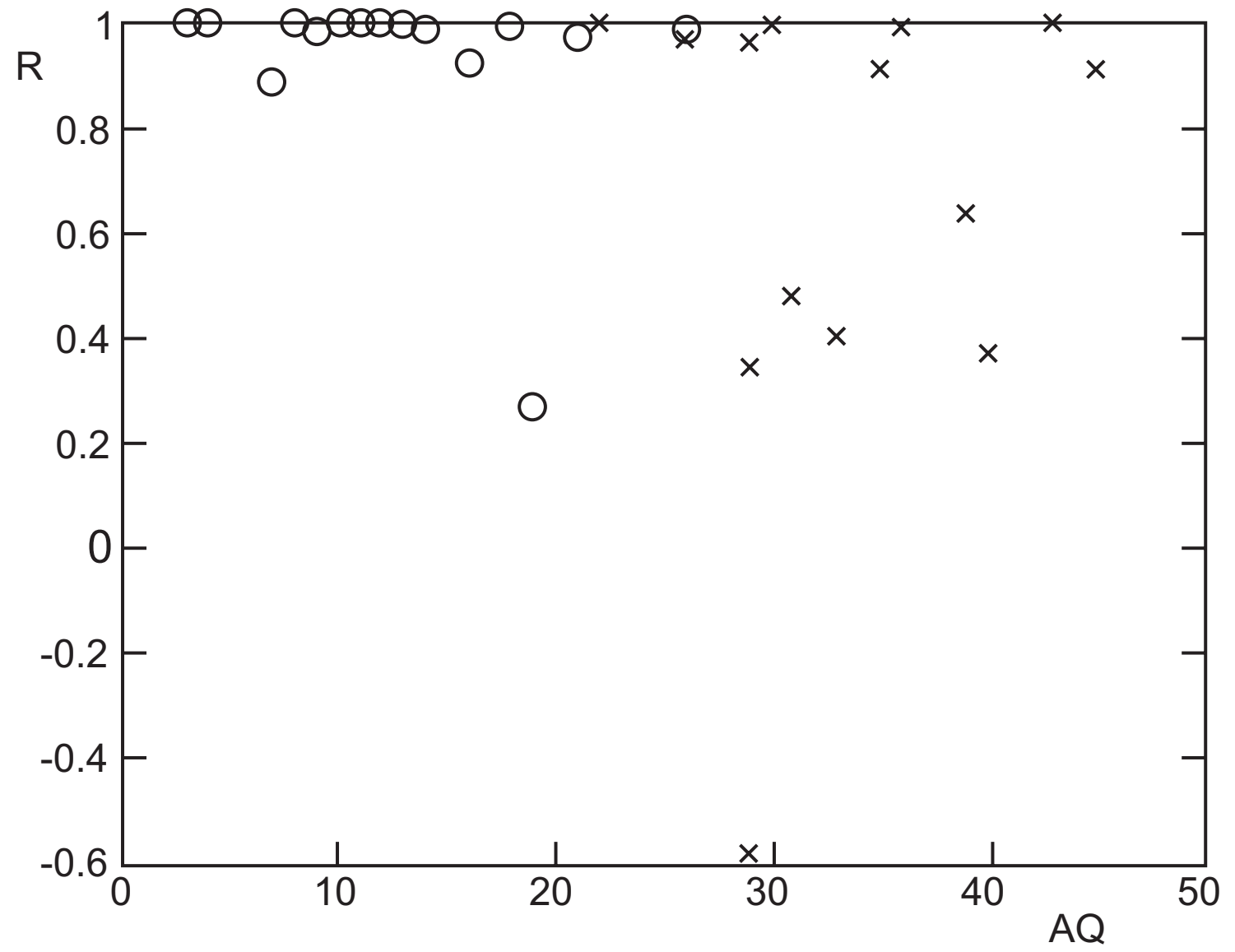

Figure 5 